\title{
Spatial Control over Chemical Functionalization of Biodegradable Poly(glycolic acid) (PGA) Sutures: Bulk vs. Surface Functionalization
}

\author{
Kyung-Bok Lee, Yong-Won Lee, Dong Jin Kim, Seon Min Lee, ${ }^{\dagger}$ Seong Ihl Woo, \\ Yongseong Kim, ${ }^{\S}$ Yang-Gyun Kim, ${ }^{\dagger, *}$ and Insung S. Choi" \\ Department of Chemistry, Korea Atwanced Institute of Science and Technologv (KAIST), Daejeon 305-701, Korea \\ - Deparment of Biochemistrv, College of Hedicine, Chung-Ang Lnwersity, Seoul 156-756, Korea \\ ${ }^{\ddagger}$ Deparment of Chemical and Biomolecular Engineering \& Center for Cltramicrochemical Process Systems, \\ Korea Advanced Institute of Science and Technologv (KAIST), Daejeon 305-701, Korea \\ sDivision of Chemistry and Chemical Engineering, Kynthnam University, Masan, Gyeongnam 631-701, Korea \\ Received September 3, 2003
}

Key Words : Arỵl nitrene. Chemical functionalization. Biotin. Polỵ(glycolic acid). Biomaterials

Sy'nthetic aliphatic poly'esters. such as poly'(gly'colic acid) (PGA). poly'(lactic acid) (PLA), and copolymers of lactic and glycolic acids (PLGAs), have widely been used in the biomedical fields. including drug delivery sy stems and tissue engineering. ${ }^{\prime}$ In tissue engineering. mammalian cells are attached to natural or synthetic (biodegradable) polymer matrices and the resulting devices are implanted in the body. ${ }^{\text {lt }}$ Compared with natural polymers. sy'nthetic polymers could be manufactured on any scale. and properties of the polymers could be tightly controlled. However the widelyused șynthetic polymers such as PGA. PLA or PLGAs do not possess natural recognition sites involved in various cellular functions (cell attachment. migration. proliferation. and differentiation). Much attention has. therefore. been paid to chemical modifications of aliphatic polyesters to improve their properties.

Chemical modifications of polymers could be classified into two categories: passive and active modifications. The objective of passive modification is creation of "inert" surfaces-the surfaces that minimize the non-biospecific adhesion of proteins and cells and prevent complications such as thrombosis. embolization. and fibrous capsule formation. ${ }^{2}$ Various surface modification methods have been developed to chemically or physically passivate biomaterials. including poly'(ethylene glycol) (PEG) grafting. exposure to radio frequency glow discharge. and oxidation. ${ }^{3}$ Active modification is a next step toward optimization of biomaterials: promotion of selective interactions between the polymers and cells (leading to interactive biomaterials). Most of the active modification strategies are based on molecular biological models of ligand/receptor binding. usually aiming at mimicking native extracellular matrix (ECM) proteins.

Several approaches have been reported to modify and/or functionalize the aliphatic polyesters. One approach relies on incorporation of monomer units presenting functional groups to the polymer backbone and derivatization of the polymer. For example. Langer and collaborators reported the

\footnotetext{
${ }^{*}$ To whom correspondence should be addressed. E-mail: ischoi a kaist.ac.kr (I. S. Choi) or ygkimmit acau.ac.kr (Y. G. Kim)
}

incorporation of a lysine moiety into PLA and the synthesis of a functionalizable polymer. poly (lactic acid-co-lysine). ${ }^{+}$ They utilized terminal amine groups of the lysine moiety to introduce biologically active groups to the polymer. such as a cell adhesion-promoting tripeptide (arginine-glycine-aspartic acid. RGD). However. this approach requires cumbersome synthesis of the monomer and achieves limited densities of grafted biologically active ligands. Other approaches to modify the aliphatic polyesters include simple coating and or covalent attachment of ligands to the surface of the polymers. ${ }^{5}$ We have recently reported a chemical approach to tailor the surface property of PGA sutures. ${ }^{6}$ The method was based on the selective surface hydrolysis of PGA sutures to generate carboxylic acid and hydroxyl groups only at the surface of the sutures. and the amide bond formation between $N$-hydroxysuccinimidyl (NHS)-activated carboxylic acid and amine-terminated molecules (biotin or RGD peptide). However, in some applications of aliphatic polyesters to biomedical areas. a long-term processing would be

(a) Surface Functionalization

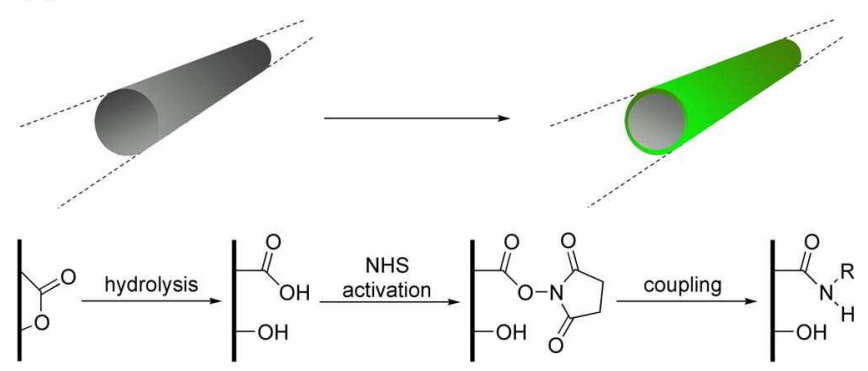

(b) Bulk Functionalization

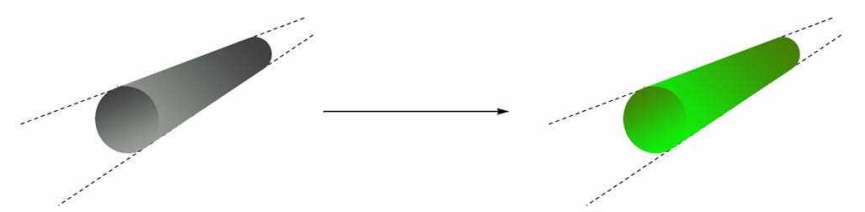

Figure 1. Schematic representation of bulk functionalization and surface functionalization. 
(a) Aryl $-\mathrm{N}_{3} \stackrel{h v}{\longrightarrow}$ Aryl- $\mathrm{N}+\mathrm{N}_{2}$

Aryl-N + R-H $\longrightarrow$ Aryl $-\mathrm{NH}_{2}$

Aryl $-\mathrm{N}+\mathrm{R}-\mathrm{H} \longrightarrow$ Aryl $-\mathrm{NHR}$

(b)

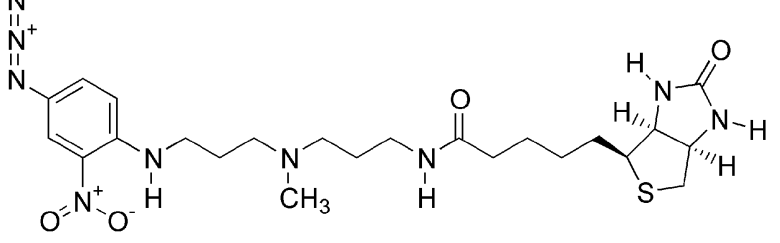

Biotin-linked nitrophenyl azide (1)<smiles>O=C(O)c1ccccc1-c1c2ccc(=O)cc-2oc2cc(O)ccc12</smiles>

Fluorescein

Jigure 2. (a) Schematic representation of photolysis of aryl aride and reactions of aryl nitrene. (b) Structures of biotin-linked nitrophenyl azide (1) and fluorescein.

necessary, and it might be problematic if the chemical integrity of surface-modified P'GA sutures would be lost over the time due to the degradation of PGA. Therefore, a complementary method to surface modification, i.e. bulk modification. would be advantageous in investigating the interactions between the polymer and cells (Figure 1).

Our approach to the bulk modification of PGA sutures is based on aryl azide chemistry (Figure 2). ${ }^{7}$ Photolysis of aryl azide yields highly reactive aryl nitrene, reactions of which include abstraction of hydrogen and insertion into a single bond (usually $\mathrm{C}-\mathrm{H}$ ) and $\mathrm{C}=\mathrm{C}$ double bonds. Generation of aryl nitrene from photolysis of aryl azide has been used as a synthetic platform of various photoactivatable cross-linkers." The photoactivatable cross-linkers are widely used to label nucleic acids and to link proteins and other biomolecules in biology laboratories. "In this study, as a proof-of concept we used commercially available biotin-linked nitrophenyl azide (1) $[N$-(4-azido-2-nitrophenyl)- $N$ '-( $N$-D-biotinyl-3-aminopropyl)- $N$-methyl-1,3-propanediamine] ${ }^{16}$ to modify the P'GA sutures. The compound $\mathbf{1}$ is converted into the corresponding aryl nitrene in the presence of UV-Visible light (254 nm), and is known to replace $\mathrm{C}-\mathrm{H}$ or $\mathrm{C}-\mathrm{C}$ bonds.

The bulk modification of the PGA sutures by biotin-linked aryl azides was characterized by confocal fluorescence microscopy. Figure 3 shows fluorescence micrographs of the reported amide formation, surface functionalization, (rigure 3a) and biotin-functionalized PGA sutures by the reaction of aryl nitrene for $1 \mathrm{~min}$ (Figure 3 b). Depth profiling analysis of the PGA sutures clearly confirms that the derivatization occurred in bulk, which is complementary to the surface modification of PGA sutures (Figures $3 \mathrm{c}$ and $\mathrm{e}$ ). We used the biotin-linked aryl azide as a model system, but various
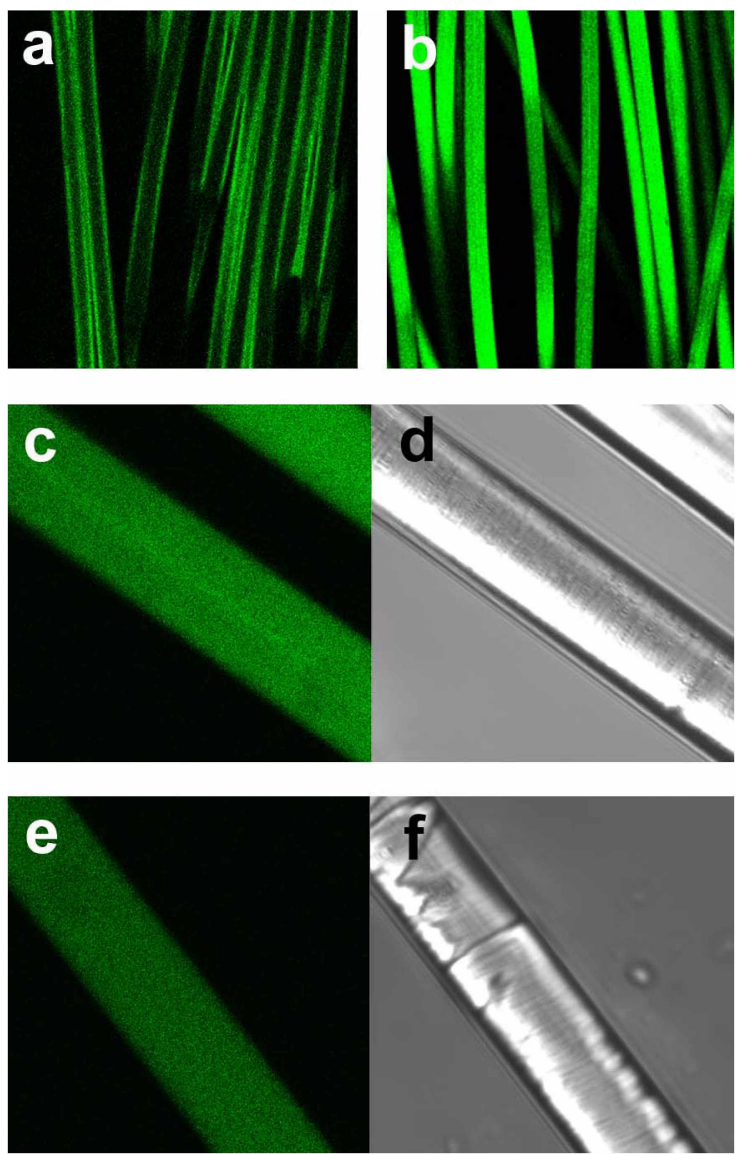

Figure 3. Fluotescence micrographs of I'( $\mathrm{A} A$ sutures after (a) surlace functionalization and (b) bulk lunctionalization. Opticallysectioned confocal micrographs at the center of PG $\triangle \wedge$ sutures (c and c) and optical micrographs of P(iA sutures ( $d$ and $f$ ) by the reaction with biotin-linked nitrophenyl azide for $1 \mathrm{~min}$ and $8 \mathrm{~min}$. respectively.

extensions will be feasible, including amine-terminated or NHS ester-terminated aryl azides for a subsequent linking. and NIA (nitrilotriacetic acid)-linked aryl azides for protein attachment.

The absorbance spectrum of the compound 1 shows $\lambda_{\text {nux }}$ at 261 and $473 \mathrm{~nm}\left(\varepsilon_{\mathrm{N} 1}=19200\right.$ and $3900 \mathrm{M}^{-1} \mathrm{~cm}^{-1}$, respectively). ${ }^{10}$ Irradiation at longer wavelength $(366 \mathrm{~nm})$ or lower temperature $\left(0^{\circ} \mathrm{C}\right)$ also yielded the bulk functionalization. Control experiments where the compound 1 was photolyzed before the mixing with $\mathrm{P}^{3} \mathrm{GA}$ sutures showed that the washing steps removed all photolyzed biotin not coupled to the l'GA sutures.

Research on biomaterials would be advanced by the synthesis of new materials and the modification of existing materials. In the modification of biomaterials, control over surface and bulk modification would make it possible to define and tailor chemical properties of the biomaterials with precision of spatial control. ${ }^{11}$ [n this note, we reported a simple chemical method for bulk functionalization of aliphatic polyesters: biotinylation of poly(glycolic acid) sutures based on aryl azide chemistry. The strategy reported can be generalized to bulk functionalization of any polymer-based biomaterials and be extended to introduction of biologically- 
active ligands (peptides. proteins. or nucleic acids) by subsequent coupling reactions. In addition. bulk functionalization is complementary to surface functionalization. which would give an opportunity in achieving in-depth understanding of cellular interactions with biomaterials

\section{Experimental Section}

The biotin-linked nitrophenyl azide was chosen as a model ligand because the attachment of the biotin could be easily detected by a complexation with a fluorophore-labeled (strept)avidin. and the biotin-(strept)avidin system is a powerful biological tool in a variety of bioanalytical applications: the interaction between biotin and streptavidin is biospecific and strong $\left(\mathrm{K}_{\mathrm{D}}=10^{-15} \mathrm{M}\right)$. and the association is very rapid and unaffected by extremes of $\mathrm{pH}$, organic solvents. and other denaturing agents. ${ }^{12}$ The dissociation of a biotin from (strept)avidin requires harsh chaotropic agents and low $\mathrm{pH}(6.0 \mathrm{M}$ guanidine hydrochloride, $\mathrm{pH} 1.5)$

Materials. Poly (glycolic acid) (PGA) sutures (Surgisorb ${ }^{\text {(i) }}$ SV013) was purchased from Samyang Co.. Korea. Biotinlinked nitrophenyl azide (1) [ $N$-(4-azido-2-nitrophenyl)- $N$ :( $N$-D-biotinyl-3-aninopropyl)- $N$ '-methyl-1,3-propanediamine] and fluorescein-conjugated streptavidin were purchased front Pierce.

Bulk Modification of PGA Sutures. PGA sutures are composed of entangled fibers ( $13 \mu \mathrm{m}$ in diameter) and the fibers were. therefore, disentangled before the use. The fibers were washed with hexane and distilled water. The compound $1(0.5 \mathrm{mg})$ was dissolved in distilled water. and the solution was added to a quartz tube containing the PGA fibers and the mixture was irradiated by UV light $(254 \mathrm{~nm}$. Rayonet photochemical mini-reactor, Model RMR-600). After the irradiation for 1.2 . 4 , or $8 \mathrm{~min}$ at room temperature. the fibers were thoroughly washed with 2 . butanol and distilled water.

Streptavidin Binding to Biotin-Attached PGA Sutures. The attachment of the biotin was characterized by confocal fluorescence microscopy: The modified PGA sutures were incubated in a phosphate-buffered saline (PBS) solution (pH 7.4) of fluorescein-conjugated streptavidin containing $0.1 \%$ $(\mathrm{w} / \mathrm{v})$ bovine serum albumin (BSA) and $0.02 \%(\mathrm{v} / \mathrm{v})$ Tween 20 at room temperature for $1 \mathrm{hr}$ (See Figure 2 for the structure of fluorescein). The PGA sutures were collected. washed several times with PBS and distilled water. and dried under reduced pressure. Fluorescence microscopy was performed on a LMS 510 confocal microscope (Carl Zeiss) $\left(\lambda_{\mathrm{ex}}=490 \mathrm{~nm} . \lambda_{\mathrm{em}}=520 \mathrm{~nm}\right)$

Acknowledgment. This work was supported by the Kyungnam University Research Fund. 2003. We thank the Korea Basic Science Institute (KBSI) for confocal fluorescence microscope analysis

\section{References and Notes}

1. (a) Uhrich. K.: Cannizzaro. S. M.: Langer. R.: Shakesheff. K. M.
Chent. Rev: 1999. 99. 3181. (b) Langer. R.: Vacanti. J. P. Science 1993. 260. 920. (c) Wong. W. H.: Mconey. D. I. In Smthetic Biodegradable Polmer Scaffolds: Atala. A.. Mooney. D. J. Vacanti. I. P.. Langer. R.. Eds.: Birkhäuser: Boston. 1997: pp 5182. (d) Kimura, Y. In Bionedical Applications of Polymeric Materials: Tsuruta. T. Hayashi, T, Kataoka, K.. Ishihara, K.. Kimura. Y., Eds., CRC Press: Boca Raton, 1993: pp 163-190. (e) Jeong. Y.-I.: Shim. Y.-H.: Song. K. C.: Park. Y.-G.: Ryu. H.-W: Nah. J.W. Bull. Korean Chem. Soc. 2002. 23. 1579.

2. Anderson. T. M.: Spilizewski. K. L.: Brunstedt. M. R.: Miller. K. M.; Marchant, R. F. In Artificial Organs, Andrade, J. D.. Brophy. J. J.. Detmer, D. E., Kim. S. W. Normann, R. A.. Olsen, D. B.. Stephen. R. L.. Eds.: VCH Publishers. Inc.: New York. 1987: pp $687-700$.

3. (a) Desai. N. P.: Hubbell. J. A. Pohnt Mater Sci. Eng. 1990. 62. 731. (b) Ertel. S. I.: Ratner. B. D.: Horbett. T. A. J. Biomed Hater: Res. 1990, 24. 1637. (c) Rasmussen, J. R.: Stedronsky. E. R: Whitesides, G. M. $J$. Am. Chem. Soc. 1977, 99. 4736. (d) Ikada. Y. Biontaterials 1994, 99,4736.

4. (a) Cook. A. D.: Hrkach. J. S.: Gao. N. N.: Iohnson1. I. M.: Pajłani. U. B.: Cannizzaro. S. M.: Langer. R. J. Bionted Mater Res. 1997. 35. 513. (b) Barrera. D.: Zylstra. E.: Lansbury. P.: Langer. R. $J$. Am. Chem. Soc. 1993. 115. 11010.

5. (a) Quirk. R. A.: Chan, W. C.: Davies, M. C.: Tendler, S. J. B.: Shakesheff. K. M. Bionaterials 2001, 22,865. (b) Kautmann. P. M.: Heimrath. S.: Kiml. B. S.: Mooney. D. T. Cell Transplant 1997. 6. 463. (c) Saxena. A. K.: Marler. T.: Benvenuto. M.: Willital. G. H.: Vacanti. J. P. Tissue Eng 1997. 5. 525. (d) Chen. G.: Ushida T.: Tateishi, T. Chem Commm 2000, 16, 1505. (e) Yang, J Bei. J.: Wang. S. Bionaterials 2002, 23, 2607. (f) Zhu. $\mathrm{H}$. Ji. J.: Lin. R: Gao, C:Feng, L; Shen. J. Biontaterials 2002, 23. 3141. (g) Cai. K.: Yao. K.: Lin. S.: Yang. Z.: Li. X.: Xie. H.: Qing. T.: Gao. L. Biontaterials 2002. 23. 1153 . (h) Cai. K: Yao. K: Cui. Y: Yan1g. Z.: Li. X.: Xie. H.: Qing. T.: Gao. L. Biomaterials 2002. 23. 1603. (i) Gao, J Niklason, L; Langer, R. J. Biomed. Mater Res. 1998. $+2,417$

6. Lee. K.-B.; Yoon. K. R; Woo. S. I.: Choi. I. S. J. Pham. Sci 2003. 92.233

7. (a) Gritsan. N. P.: Platz. M. S. Adw: Phns Org Chent 2001. 36 255. (b) Schuster. G. B.: Platz. M. S. Ad. Photochem 1992. 17. 69. (c) Poe, R.; Schnapp, K; Young, M. J. T; Grayzar. J; Platz. M. S. J. Am. Chem. Soc. 1992. 114, 5054. (d) Iddon. B.; MethCohn. O.: Scriven. E. F. V; Suschitzky, H; Gallagher, P. T. Angew: Chent. Int Ed 1979. 18. 900. (e) Bayley. H.: Knowles. I. R Methods Enztmol. 1977. 46. 69. (f) Staros. J. V. Thends Biochent. Sci. 1980. 5. 320. (g) Park. S. H. Bull. Koman Chem. Soc. 2003. 24.253

8. A recent report investigated the mechanism of aryl azide chemistry in an aqueous environment. where the photolysis of $3-$ hydrosyphenyl azide was shown to generate either a ketenimine or azepinone intermediate that reacted with nucleophiles. See: Buchmuller. K. L.: Hill. B. T.: Platz. M. S.: Weeks. K. M. $J$. Am. Chem. Soc. 2003, 125. 10850 .

9. (a) Ofengand, J; Schwartz, I; Chinali. G.; Hixson, S. S.; Hixson. S. H. Methods Enzlmol 1977, +6.683. (b) Burgin. A. B.: Pace, N. R. EMBOO J. 1990. 9. 411 l. (c) Wang. J.-F.: Downs. W. D.: Cech. T. R. Science 1993. 260. 504. (d) Pinard. R.: Heckman. J. E: Burke. J. M. J. M fol Biol. 1999. 287. 239. (e) Chen. J. L.: Nolan. J. M.; Harris, M. E.; Pace, N. R. El BBO J. 1998, 17. 1515.

10. For the synthesis of the compound 1, See: Forster. A. C.: McInnes. J. L.; Stingle, D. C.: Svmons. R. H. Sucleic Acids Res. 1985, 13,745

11. (a) Bontempo. D.: Tirelli. N.: Feldmant. K.: Masci. G.: Crescenzi. V: Hubbell. J. A . Ach Hater: 2002. 14. 1239. (b) Bontempo. D: Tirelli. N.: Masci. G.: Crescenzi. V: Hubbell. T. A. Macronol. Rapid Commm. 2002. 23.417. (c) Kim, D. J.: Heo. J.-y.: Kim, K S.) Choi, I. S. Macromol Rapid Commun. 2003, 24. 517.

12. Hong. M.-Y: Lee, Di; Yoon, H. C.: Kim, H.-S. Bull Korean Chent. Soc. 2003. 24. 1197. 